\title{
FIRM SPECIFIC FACTORS DAN PROFITABILITAS SUB-SEKTOR PROPERTI DI INDONESIA
}

\author{
Muhammad Madyan, Putri Yanti Lestyarini, \& Novian Abdi Firdausi \\ Universitas Airlangga \\ E-mail: muhammadmadyan@gmail.com
}

\begin{abstract}
ABSTRAK
Penelitian ini menganalisis pengaruh firm specific factors terhadap profitabilitas sub-sektor properti dan real estate yang terdaftar di BEl selama tahun 2010-2015. Firm specific factors diukur melalui perhitungan liquidity, financial leverage, firm size, dan firm growth sebagai determinan yang umumnya digunakan. Penelitian ini menggunakan metode purposive sampling terhadap 33 perusahaan yang memenuhi kriteria penelitian, yakni perusahaan yang ada dalam sub-sektor properti dan real estate di BEl secara konsisten serta menerbitkan laporan keuangan secara rutin selama masa penelitian. Analisis dilakukan menggunakan regresi linier berganda dengan hasil penelitian menunjukkan liquidity dan financial leverage berpengaruh negatif terhadap profitabilitas, sedangkan firm size dan firm growth berpengaruh positif terhadap profitabilitas.
\end{abstract}

Kata kunci: financial leverage, firm growth, firm size, firm specific factors, liquidity, property real estate

\begin{abstract}
This study analyzes effects of firm specific factors to the profitability of property and real estate sub-sector which listed in BEI in time period of 2010-2015. Firm specific factors are measured with liquidity, financial leverage, firm size, and firm growth as generally used determinants. This reasearch used purposive sampling method at 33 firms which fulfill the research criterions, which are firms listed consistently in BEl's property and real estate subsector, also publishing financial statements routinely during research period. Analysis proceeded by using multiple linear regression with study results show that liquidity and financial leverage have negative effects to profitability, while firm size and firm growth have positive effects to profitability.
\end{abstract}

Keywords: financial leverage, firm growth, firm size, firm specific factors, liquidity, property and real estate 


\section{Muhammad Madyan \\ Putri Yanti Lestyarini \\ Novian Abdi Firdausi}

\section{PENDAHULUAN}

Indonesia adalah satu negara dengan pertumbuhan ekonomi yang tinggi dengan tingkat inflasi aset yang tinggi. Nilai properti dan real estate meningkat drastis sejak tahun 90-an dengan mengalirnya permodalan asing (Ooi \& Liow, 2004). Properti dan real estate adalah salah satu sub-sektor yang menarik untuk kegiatan investasi, harga tanah dan bangunan semakin naik seiring berjalannya waktu karena jumlah penambahan lahan properti relatif tetap dengan permintaan pasar yang makin meningkat seiring bertambahnya populasi. Terlebih harga properti di Indonesia masih relatif murah jika dilihat dalam lingkup ASEAN (Diaz \& Hindro, 2017; Lee, 2014).

Ooi dan Liow (2004) dijelaskan dorongan investor untuk masuk dalam sub-sektor properti dan real estate di Indonesia adalah potensi laba permodalan yang baik dibandingkan pendapatan sewa properti. Hal yang sangat dikhawatirkan dalam industri real estate adalah menurunnya tingkat penjualan, dan imbasnya adalah penurunan profitabilitas perusahaan. Perusahaan diharapkan dapat mempertahankan kelangsungan hidupnya, menghindari kesulitan keuangan dan kebangkrutan, memenangkan persaingan, menarik minat investor, serta melakukan ekspansi usaha yang lebih luas lagi dengan meningkatkan profitabilitas (Nasuha at al., 2018; Bhutta \& Hasan, 2013).

Masing-masing perusahaan memiliki cara tersendiri untuk meraih profit yang besar. Avdalović (2018) menjelaskan bahwa profitabilitas perusahaan dipengaruhi oleh variabelvariabel internal maupun eksternal perusahaan. Firm specific factors adalah faktor-faktor keuangan yang spesifik di perusahaan, tidak ada standar maupun penetapan yang baku untuk faktor-faktor ini sehingga pengukuran variabel-variabel yang ada ditentukan sendiri dan disesuaikan dengan dasar literatur yang ada. Contohnya pada pengukuran firm size, umumnya pengukuran firm size ini menggunakan logaritma dari total aset, tetapi ada juga pengukuran firm size menggunakan logaritma total sales (Diaz \& Hindro, 2017; Hossain \& Ali, 2012; Bhutta \& Hasan; 2013)

Penelitian terdahulu yang dilakukan Algushin (2015) menyimpulkan bahwa financial leverage berpengaruh negatif, sedangkan firm growth dan firm size berpengaruh positif pada profitabilitas 25 industri di Jordania. Sunarto dan Budi (2009) memiliki hasil yang sama dengan Algushin, dengan objek penelitian 21 Perusahaan Daerah Air Minum di Jawa Tengah. Ambarwati at al. (2015) serta Nugroho dan Pangestuti (2011) meyimpulkan bahwa liquidity dan firm size berpengaruh positif, firm growth dan leverage berpengaruh negatif terhadap industri manufaktur di BEI. Berdasarkan penjelasan diatas, maka penelitian ini bertujuan untuk mengetahui pengaruh firm specific factors yang diukur melalui financial 


\section{Jurnal Manajemen Teori dan Terapan \\ Tahun 12. No. 2, Agustus 2019}

leverage, liquidity, firm growth, dan firm size terhadap profitabilitas perusahaan sub-sektor properti dan real estate.

Riset mengenai firm specific factor umumnya mebahas masalah manajemen strategik, dengan berbagai pendekatan seperti resource-based value (Chatzoglou at al., 2018), studi komparasi dengan industry-specific factor (Hawawini at al., 2003), sebagai determinan investasi (Ajide, 2017), dan sebagainya, namun penelitian ini menggunakan sudut pandang manajemen keuangan dalam pengukuran dan analisisnya. Penelitian-penelitian sebelumnya juga dilakukan di berbagai objek penelitian, seperti industri asuransi di Taiwan (Lee, 2014), sektor pangan di Pakistan (Bhutta \& Hasan, 2013), perusahaan di Bangladesh (Hossain \& Ali, 2012), serta sektor asuransi di Uni Emirat Arab (Banerjee \& Majumdar, 2018).

Meskipun sub-sektor properti dan real estate di Indonesia relatif sering digunakan sebagai objek penelitian (Diaz \& Hindro, 2017; Setiawanta, 2016; Mayasari, 2012), jarangnya penelitian yang membahas firm specific factor secara spesifik menjadi research gap dalam penelitian ini. Penelitian ini dapat membantu pertimbangan pihak-pihak stakeholder dalam pengambilan keputusan melalui sudut pandang firm specific factors, dengan tujuan evaluasi dan analisis agar dapat meraih profit lebih banyak di masa mendatang. Penelitian ini juga menambah wawasan keilmuan dibidang manajemen keuangan dan dapat digunakan sebagai bahan rujukan bagi penelitian-penelitian selanjutnya.

\section{LANDASAN TEORI}

Banyak sekali studi mengenai determinan performa keuangan perusahaan secara spesifik, dengan sudut pandang dan lingkup yang berbeda-beda. Kondisi keuangan pada tiap skala ekonomi memiliki berbagai detrminan yang spesifik pada lingkupnya masing-masing. Firm Specific Factors adalah bahasa umum tentang variabel-variabel penentu performa keuangan perusahaan. Financial leverage, liquidity, firm growth dan firm size adalah variabel penentu yang umumnya digunakan dalam penelitian dengan pembahasanpembahasan yang serupa, seperti dalam Avdalović (2018), Bhutta dan Hasan (2013), Hossain dan Ali (2012), Kaya (2015), Banerjee dan Majumdar (2018), Diaz dan Hindro (2017), Nasuha at al. (2018), Lee (2018), Setiawanta (2016), serta Karina dan Khafid (2015).

Makna profitabilitas adalah kemampuan perusahaan untuk menghasilkan laba (Warren at al., 2006). Profitabilitas dapat menjadi standar penilaian efektivitas pengelolaan perusahaan, pada umumnya profitabilitas diukur melalui return on asset (ROA). Sudana (2011) mengungkapkan bahwa ROA menunjukkan kapabilitas perusahaan dalam menggunakan seluruh aktiva yang dimiliki untuk menghasilkan laba bersih. Profitabilitas juga mampu mendukung struktur modal, Chandra (2014) menjelaskan perusahaan besar dengan 


\section{Muhammad Madyan \\ Putri Yanti Lestyarini \\ Novian Abdi Firdausi}

keuangan yang kuat cenderung memiliki kekuatan untuk memperoleh dana murah. Hal ini didasari oleh kepercayaan kreditur yang kuat pula, sehingga kreditur bersedia memberi hutang dengan tingkat bunga yang relatif rendah.

Leverage secara harfiah adalah 'pengungkit' (Nurinna, 2008), sehingga analogi dalam financial leverage adalah meringankan beban keuangan perusahaan menggunakan 'pengungkit' berupa instrumen hutang dan ekuitas dengan tujuan meraih profit yang lebih besar di masa mendatang (Pareja, 2010). Secara teori, financial leverage adalah jumlah proporsi hutang yang diandalkan perusahaan, semakin banyak pembiayaan hutang yang digunakan dalam struktur modal perusahaan maka semakin besar pula financial leveragenya (Ross at al., 2009). Mas'ud (2008) menjabarkan bahwa financial leverage dapat meningkatkan profitabilitas perusahaan, financial leverage mengamankan kendali operasional perusahaan karena struktur pemegang saham tidak berubah. Selain itu, pembayaran bunga pinjaman juga dapat mengurangi pajak yang harus dibayar perusahaan.

Liquidity adalah kemampuan perusahaan untuk melunasi kewajiban finansialnya dalam jangka pendek tanpa tekanan yang berlebihan (Ross at al., 2009). Warren at al. (2006) menyatakan bahwa perusahaan yang tidak mampu membayar hutangnya ketika jatuh tempo akan kesulitan mendapat kredit maupun modal baru dari shareholder, dampaknya adalah penurunan profitabilitas perusahaan. Liquidity mengukur kemampuan aktiva lancar dalam memenuhi kewajiban lancar, tetapi aktiva lancar yang berlebih menandakan banyaknya dana menganggur yang harusnya dapat diinvestasikan dan menghasilkan laba, sehingga berdampak pada profitabilitas perusahaan (Putrawan at al., 2015; Ambarwati at al., 2015).

Firm growth atau pertumbuhan perusahaan merupakan pengukuran peningkatan nilai perusahaan melalui tingkat pertumbuhan total penjualan dan/atau pendapatan yang dimiliki perusahaan. Semakin tinggi tingkat pertumbuhan perusahaan, semakin tinggi pula indikasi peningkatan profit perusahaan (Sunarto \& Budi, 2009). Tetapi pertumbuhan perusahaan harus diikuti dengan pertimbangan kontngensi resiko atas kegagalan ekspansi, karena ekspansi berdampak pada beban perusahaan dalam menutupi biaya dan proyeksi return profit yang diharapkan (Nugroho \& Pangestuti, 2011).

Firm Size adalah besar kecilnya ukuran perusahaan yang diukur melalui total aset perusahaan, aset perusahaan digunakan perusahaan untuk kegiatan operasionalnya. Bhutta dan Hasan (2013) menjelaskan bahwa firm size berkorelasi terhadap profitabilitas, 
karena firm size melambangkan kekuatan relatif dari segi finansial dan legal. Banerjee dan Majumdar (2018) serta Diaz dan Hindro (2017) juga menjelaskan bahwa variabel firm size memiliki korelasi yang besar pada performa perusahaan, dengan beberapa temuan bahwa firm size pada lingkup negara tertentu bisa memiliki korelasi performa yang berbeda-beda.

Berdasarkan teori-teori dan literatur yang dijelaskan sebelumnya, maka hipotesis yang dirumuskan adalah: (1) Financial leverage berpengaruh positif terhadap profitabilitas. (2) Liquidity berpengaruh negatif terhadap profitabilitas. (3) Firm growth berpengaruh positif terhadap profitabilitas. (4) Firm size berpengaruh positif terhadap profitabilitas.

\section{METODE}

Penelitian menggunakan pendekatan kuantitatif karena meneliti hubungan kausalitas antar variabel. Variabel dependen dalam penelitian ini adalah profitabilitas yang diukur melalui ROA, yakni laba bersih dibagi total aktiva. Variabel independen yang pertama adalah financial leverage (FL) yang diukur melalui debt ratio, yakni total hutang dibagi total aktiva. Variabel yang kedua adalah liquidity (CR) yang diukur melalui current ratio, yakni asset lancar dibagi kewajiban lancar. Selanjtutnya variabel ketiga adalah firm growth (GROWTH) yang diukur melalui selisih perubahan $(\Delta)$ total pendapatan tahun ke- $\dagger$ dibandingkan dengan total pendapatan tahun sebelumnya (t-1). Variabel terakhir adalah firm size (SIZE) yang diukur melalui logaritma total asset.

Jenis data yang digunakan adalah kombinasi data time series dan cross section. Data yang diambil bersumber dari data sekunder berupa laporan keuangan perusahaan sampel terpilih pada sub-sektor properti dan real estate yang listing di BEl dalam kurun waktu 20102015. Pemilihan sampel data menggunakan teknik purposive sampling untuk mendapatkan representasi populasi yang sesuai dengan kriteria penelitian, yakni perusahaan yang ada secara konsisten dalam listing sub-sektor properti dan real estate dan menyajikan laporan keuangan secara lengkap dan rutin dalam periode waktu 2010-2015. Model analisis dijabarkan sebagai berikut:

$$
\mathrm{ROA}=+{ }_{1} \mathrm{FL}_{\text {it }}+{ }_{2} \mathrm{CR}_{\text {it }}+{ }_{3} \mathrm{GROWTH}_{\text {it }}+{ }_{4} \mathrm{SlZE}_{\text {it }}+\mathrm{e}
$$

Keterangan:

$\begin{array}{ll}\text { ROA }_{\text {it }} & =\text { Profitabilitas perusahaan i pada periode } \dagger \\ & =\text { Konstanta regresi } \\ & =\text { Koefisien regresi } \\ & =\text { Financial Leverage perusahaan i pada periode } \dagger \\ \text { FLit }_{\text {it }} & =\text { Liquidity perusahaan i pada perode } \dagger \\ \text { GROWTH }_{\text {it }} & =\text { Firm growth perusahaan i pada periode } \dagger \\ \text { SIZE }_{i t} & =\text { Firm size perusahaan i pada periode } \dagger \\ \mathrm{e} & =\text { Error term }\end{array}$




\section{Muhammad Madyan \\ Putri Yanti Lestyarini \\ Novian Abdi Firdausi}

Tahapan analisis yang dilakukan adalah: (1) Menetapkan perusahaan sampel. (2) Melakukan pre-input data sesuai dengan pengukuran masing-masing variabel. (3) Melakukan analisis statistik deskriptif. (4) Melakukan uji asumsi klasik yang meliputi uji normalitas, uji multikolienaritas, uji heteroskesdasitas, dan uji autokorelasi. (5) Pengujian hipotesis menggunakan uji † (parsial) pada model analisis.

\section{HASIL DAN PEMBAHASAN}

Populasi perusahaan properti dan real estate yang listing di Bursa Efek Indonesia hingga tahun 2015 berjumlah 49 perusahaan, setelah disaring melalui teknik purposive sampling, diperoleh 33 perusahaan yang memenuhi kriteria-kriteria penelitian.

Tabel 1.

Tabel Statistik Deskriptif

\begin{tabular}{lllll}
\hline & Minimum & Maximum & Mean & Std. Deviation \\
\hline Profitability & $-0,103$ & 0,316 & 0,0597 & 0,05714 \\
Leverage & 0,066 & 0,740 & 0,4132 & 0,15533 \\
Liquidity & 0,195 & 3,985 & 1,7163 & 0,89725 \\
Growth & $-0,655$ & 1,727 & 0,2690 & 0,42390 \\
Size & 25,203 & 31,353 & 28,5911 & 1,54347 \\
\hline Valid $n$ & 198 & & & \\
\hline
\end{tabular}

Observasi dilakukan sebanyak 198 kali pada 33 perusahaan sampel. Nilai rata-rata profitabilitas menunjukkan angka $6 \%$, dengan nilai dispersi sebesar $5,7 \%$. Sekitar $41,3 \%$ komponen keuangan di sub-sektor bersumber dari dana pinjaman. Tingkat kenaikan pertumbuhan aset dan ukuran perusahaan cukup baik dengan nilai masing-masing sebesar $171,6 \%$ dan $285,9 \%$. Secara keseluruhan, rentang nilai rata-rata standar deviasi ada dibawah nilai rata-rata (mean), artinya kecenderungan penyimpangan data tidak seberapa jauh.

Tabel 2.

Hasil Uji T Regresi Linear Berganda

\begin{tabular}{llllll}
\hline \multirow{2}{*}{ Model } & \multicolumn{2}{l}{ Unstandarized Coefficients } & Standarized Coefficients & \multirow{2}{*}{$\dagger$} & \multirow{2}{*}{ Signifikansi } \\
\cline { 2 - 4 } & $\mathrm{B}$ & Standar Error & Beta & & \\
\hline Konstanta & $-0,130$ & 0,074 & & $-1,747$ & 0,082 \\
Leverage & $-0,034$ & 0,030 & $-0,093$ & $-1,158$ & 0,248 \\
Liquidity & $-0,004$ & 0,005 & $-0,064$ & $-0,856$ & 0,393 \\
Growth & 0,036 & 0,009 & 0,269 & 3,947 & 0,000 \\
Size & 0,007 & 0,003 & 0,190 & 2,591 & 0,010 \\
\hline R & 0,340 & & & \\
R Square & 0,116 & & & \\
\hline
\end{tabular}

Sumber : Data diolah 
Hasil pada tabel 2 menunjukkan, maka persamaan regresi linear berganda yang dihasilkan adalah:

$$
\text { ROA }=-0,13-0,034 \mathrm{FL}-0,004 \mathrm{CR}+0,036 \mathrm{GROWTH}+0,007 \mathrm{SIZE}+\mathrm{e}
$$

Nilai signifikansi pada Tabel 2 menunjukkan bahwa variabel financial leverage dan liquidity menunjukkan hasil yang tidak signifikan, sementara variabel firm growth dan firm size berpengaruh secara signifikan terhadap profitabilitas. Nilai koefisien determinasi sebesar 0,116 menunjukkan bahwa variabel dependen Profitabilitas perushaan mampu dijelaskan sebesar $11,6 \%$ oleh variabel-variabel dependen.

Pengaruh financial leverage yang negatif terhadap profitabilitas mengartikan bahwa subsektor properti dan real estate sesuai dengan teori pecking order, dimana perusahaan lebih memilih laba ditahan (permodalan internal) sebagai pilihan pertama dalam permodalan. Jika perusahaan lebih memilih permodalan internal maka perusahaan akan mengurangi proporsi hutang dalam struktur modalnya (Çekrezi, 2013), sehingga pengaruh leverage menjadi negatif. Kondisi sub-sektor properti dan real estate yang sedang dalam masa recovery dari krisis keuangan di tahun 2008 membuat perusahaan properti memutar otak untuk menjaga keuangannya (Chandra, 2014). Kebijakan pengambilan hutang untuk dijadikan permodalan menjadi meragukan dan berdampak pada pengaruh yang tidak signifikan. Pengaruh negatif mendukung kesimpulan penelitian Nugroho dan Pangestuti (2011), Sunarto dan Budi (2009), serta Algushin (2015).

Pengukuran liquidity melalui current ratio menghasilkan nilai pengaruh negatif, mendukung hasil penelitian Putrawan (2015) yang menyimpulkan tingginya current ratio mengarah pada alokasi aktiva lancar yang tinggi pula, sehingga ada trade off alokasi dana yang harusnya diinvestasikan untuk menambah laba. Di sisi lain Nugroho dan Pangestuti (2011) menemukan pengaruh positif current ratio pada profitabilitas, dengan hasil tingkat likuiditas yang tinggi dapat mempermudah perusahaan untuk mendapatkan modal melalui hutang.

Diaz dan Hindro (2017) juga dijelaskan bahwa tingginya current ratio dapat menyebabkan biaya tambahan atas pemeliharaan aset. Pendapat ini sangat relevan dalam sub-sektor properti dan real estate dimana properti yang dijual harus selalu dirawat agar dapat meyakinkan pembeli, terlebih apabila developer memiliki stok persediaan properti yang banyak.

Ambarwati at al. (2015) menemukan pengaruh liquidity yang tidak signifikan karena banyak perusahaan yang keuangannya efisien meskipun current ratio-nya rendah. Nilai signifikansi financial leverage dan liquidity yang tidak signifikan juga disebabkan oleh kondisi 


\section{Muhammad Madyan \\ Putri Yanti Lestyarini \\ Novian Abdi Firdausi}

perekonomian yang fluktuatif. Diaz dan Hindro (2017) menjelaskan bahwa dalam jangka waktu 2012-2013 properti dan real estate mengalami perkembangan yang pesat. 26 dari 45 perusahaan properti mengalami kenaikan profit lebih dari 50\%. Bahkan dalam kurun waktu tahun $2011-2013$, kenaikan harga properti mendekati 30\% per tahun.

Di lain sisi, suku bunga Bank Indonesia pada tahun 2012-2013 sebesar 5,75\% dengan proporsi kredit rumah/properti sebesar $46 \%$ dari total kredit yang disalurkan perbankan di Indonesia (Van der Schaar, 2015). Lambatnya pertumbuhan perekonomian di tahun 2013 membuat Bank Indonesia mewaspadai kredit properti agar krisis subprime mortgage tidak terulang di Indonesia. Hasilnya adalah kebijakan BI untuk menaikkan down payment pembelian properti, membatasi pembelian properti lebih dari satu, melarang pinjaman untuk properti yang sedang dibangun, dan menaikkan suku bunga menjadi 7,5\%. Sub-sektor properti dan real estate terkena dampak besar dari peristiwa ini, dengan penurunan tajam profitabilitas penjualan properti sebesar 40,1\% di tahun 2014 menjadi 26,6\% di tahun 2015 (Diaz \& Hindro, 2017).

Variabel firm growth menunjukkan pengaruh positif terhadap profitabilitas perusahaan, hal ini sejalan dengan Avdalović (2018) yang menyatakan firm growth adalah prediktor utama dalam menjelaskan profitabilitas perusahaan, terlebih ketika perusahaan memiliki aset dengan umur penyusutan yang panjang. Hasil yang sama juga ditemukan oleh Diaz dan Hindro (2017) menggunakan fixed effect (FE) model dan ordinary least square (OLS), dengan kesimpulan bahwa perusahaan properti dan real estate dapat meningkatkan profitabilitas melalui pemberian diskon dan skema pembayaran yang lebih fleksibel untuk menarik konsumen dan mengembangkan perusahaan.

Firm size atau bisa diartikan dengan ukuran perusahaan berpengaruh positif pada profitabilitas. Chandra (2014) menyebutkan bahwa semakin besar ukuran perusahaan maka semakin kuat fundamental keuangan perusahaan, keuatan fundamental dapat mengurangi cost of fund perusahaan dan memperbesar potensi perusahaan untuk menambah hutang modal.

Firm growth dan firm size sama-sama memiliki pengaruh positif pada profitabilitas, hasil ini sejalan dengan Bhutta dan Hasan (2013). Diaz dan Hindro (2017) mengartikan size dan growth sebagai kekuatan relatif yang dimiliki oleh sevah perusahaan, kepemilikan aset yang besar mampu meningkatkan jejaring dan kekuatan posisi perusahaan di pasar serta optimalisasi operasi perusahaan. Semakin besar ukuran dan pertumbuhan perusahaan properti, semakin besar pula kekuatan perusahaan dalam menambah aset (Iahan atau 


\section{Jurnal Manajemen Teori dan Terapan \\ Tahun 12. No. 2, Agustus 2019}

bangunan) untuk dikembangkan menjadi properti, selain itu perusahaan properti juga mampu membentuk anak perusahaan maupun organisasi asosiasi yang menaungi perusahaan-perusahaan properti

Nilai pengaruh firm growth yang positif serta nilai pengaruh financial leverage yang negatif (berbanding terbalik) sesuai dengan apa yang dibahas oleh Hossain dan Ali (2012), tingkat leverage yang tinggi mampu menghambat pertumbuhan perusahaan, aset yang produktif dan mampu meningkatkan profitabilitas perusahaan harusnya dibiayai menggunakan ekuitas, karena penggunaan hutang dapat meningkatkan resiko dan kerugian para stockholder.

\section{SIMPULAN}

Potensi yang ada di sub-sektor properti dan real estate sangatlah menarik. Secara logika kasar saja, tiap manusia pasti membutuhkan sebuah lokasi yang bisa dijadikan tempat tinggal. Selain itu harga tanah dan bangunan diproyeksikan akan selalu naik seiring berjalannya waktu. Potensi ini harus ditangkap oleh perusahaan-perusahaan yang bergerak di bidang properti dan real estate untuk meningkatkan profitabilitas perusahaan. Dalam rangka meningkatkan profitabilitas, perusahaan memiliki caranya tersendiri. Firm specific factors adalah sebuah sudut pandang umum tentang determinan faktor keuangan tertentu dalam sebuah perusahaan/industri.

Perusahaan dapat menganalisis performa keuangan melalui pengukuran financial leverage, liquidity, firm growth, dan firm size yang umumnya digunakan penelitian-penelitian yang ada untuk menganalisis profitabilitas perusahaan dengan menganalisis firm specific factors. Sub sektor properti dan real estate sedang mengalami pemulihan pasca krisis ekonomi 2008 dalam periode penelitian. Hasil analisis regresi linear berganda menyimpulkan bahwa financial leverage dan liquidity berpengaruh negatif terhadap profitabilitas, sedangkan firm growth, dan firm size berpengaruh positif terhadap profitabilitas.

\section{DAFTAR PUSTAKA}

Ajide, F. M. 2017. Firm-specific, and institutional determinants of corporate investments in Nigeria. Future Business Journal 3(2).

Algushin, N. A. S. 2015. Do Financial Leverage, Growth and Size Affect Profitability of Jordanian Industrial Firms Listed?. International Journal of Academic Research in Business and Social Sciences 5(4).

Ambarwati, N. S., Yuniarta, G. A., Sinarwati, N. K., 2015. Pengaruh Modal Kerja, Likuiditas, Aktivitas Dan Ukuran Perusahaan Terhadap Profitabilitas Pada Perusahaan Manufaktur 


\section{Muhammad Madyan \\ Putri Yanti Lestyarini \\ Novian Abdi Firdausi}

Yang Terdaftar Di Bursa Efek Indonesia. Jurnal IImiah Mahasiswa Akuntansi SI (JIMAT) $3(1)$.

Avdalović, S. M. 2018. Impact of Firm Specific Factors on Profitability of Industrial Grinding Companies. Economics of Agriculture 65(2).

Banerjee, R., dan Sudipa, M. 2018. Impact of firm specific and macroeconomic factors on financial performance of the UAE insurance sector. Global Business and Economics Review 20(2).

Bhutta, N. T., dan Arshad, H. 2013. Impact of Firm Specific Factors on Profitability of Firms in Food Sector. Open Journal of Accounting 2(2).

Çekrezi, Anila. 2013. Impact Of Firm Specific Factors On Capital Structure Decision: An Empirical Study Of Albanian Firms. European Journal of Sustainable Development 2(4).

Chandra, T. 2014. Faktor-Faktor Yang Memengaruhi Struktur Modal Pada Perusahaan Properti Dan Real Estate Di Indonesia. Ekuitas: Jurnal Ekonomi dan Keuangan 18(4).

Chatzoglou, P., Chatzoudes, D., Sarigiannidis, L., Theriou, G. 2018. The role of firm-specific factors in the strategy-performance relationship Revisiting the resource-based view of the firm and the VRIO framework. Management Research Review 41 (1).

Diaz, J. F. T., dan Martha, C. T. H. 2017. Factors Affecting the Profitability of Indonesian Real Estate Publicly-listed Companies. Asian Journal of Finance \& Accounting 9(1).

Hawawini, G., Subrmanian, V., Verdin, P. 2003. Is Performance Driven by Industry- Or FirmSpecific Factors? A New Look at The Evidence. Strategic Management Journal 24(1).

Hossain, F., dan Ayub, A. 2012. Impact of Firm Specific Factors on Capital Structure Decision: An Empirical Study of Bangladeshi Companies. International Journal of Business Research and Management (IJBRM)3(4).

Karina, F., dan Muhammad, K. 2015. Determinan Profitabilitas pada Perusahaan Properti dan Real Estate Go Public di Indonesia. Jurnal Dinamika Akuntansi 7(1).

Kaya, E. Ö. 2015. The Effects of Firm-Specific Factors on the Profitability of Non-Life Insurance Companies in Turkey. International Journal of Financial Studies 3(4).

Lee, C. 2014. The Effects of Firm Specific Factors and Macroeconomics on Profitability of Property-Liability Insurance Industry in Taiwan. Asian Economic and Financial Review $4(5)$.

Mas'ud, M. 2008. Analisis Faktor-Faktor Yang Mempengaruhi Struktur Modal Dan Hubungannya Terhadap Nilai Perusahaan. Jurnal Manajemen dan Bisnis (MABIS).

Mayasari, Eka Yunia. 2012. Studi Profitabilitas Pada Perusahaan Real Estate Dan Property Di BEl. Accounting Analysis Journal 1 (2).

Nasuha, N. 2018. The Determinants of Firm Profitability and Risk on Real Estate Industry. SSRN Electronic Journal. 10.2139/ssrn.3300487. 
Nugroho, E., dan Pangestuti I. R. D. 2011. Analisis Pengaruh Likuiditas, Pertumbuhan Penjualan, Perputaran Modal Kerja, Ukuran Perusahaan dan Leverage terhadap Profitabilitas Perusahaan (Studi pada Perusahaan Manufaktur yang Terdaftar pada BEI pada Tahun 2005-2009). Skripsi. Universitas Diponegoro.

Nurinna, R. 2008. Analisis Pengaruh Financial Leverage Dan Operating Leverage Terhadap Rentabilitas Perusahaan Pada PT. Panconin Cipta Perkasa Di Makassar. Skripsi. Universitas Hasanuddin.

Ooi, J. T. L., dan Kim-Hiang, L. 2004. Risk-Adjusted Performance of Real Estate Stocks: Evidence from Developing Markets. Journal of Real Estate Research 26(4).

Pareja, I. V. 2012. Leverage: Operating, Financial and Total (Slides). SSRN Electronic Journal. $10.2139 /$ ssrn.1641494.

Putrawan, P. W. Sinarwati, N. K., Purnamawati, G. A. 2015. Pengaruh Investasi Aktiva Tetap, Likuiditas, Solvabilitas, Dan Modal Kerja Terhadap Profitabilitas Perusahaan Otomotif Dan Komponen Yang Terdaftar Di Bursa Efek Indonesia Tahun 2010-2013. Jurnal IImiah Mahasiswa Akuntansi S1 (JIMAT 3(1).

Ross, S. A., Randolph, W., dan Westerfield, B. D. J. 2009. Pengantar Keuangan Perusahaan. Jakarta: Salemba Empat.

Setiawanta, Y. 2016. Profitabilitas, Likuiditas dan Nilai Perusahaan (Industri Properti dan Real Estate Yang Listed di PT. BEl pada Tahun 2011- 2014). Jurnal Penelitian Ekonomi dan Bisnis 1 (2).

Sudana, I M. 201 1. Manajemen Keuangan Perusahaan Teori Dan Praktik. Surabaya: Penerbit Erlangga.

Sunarto, S. dan Budi, A. P. 2009. Pengaruh Leverage, Ukuran dan Pertumbuhan Perusahaan Terhadap Profitabilitas. Jurnal IImiah Telaah Manajemen 6(1).

Warren, C. S. Reeve, J. M., Fees, Philip, E. 2005. Pengantar Akuntansi. 2006. Jakarta: Salemba Empat.

Van-der-Schaar, R. M. A. 2015. Analysis Indonesia's Property Market; Overview \& Foreign Ownership. [Indonesia-Investments Website]. http://www.indonesiainvestments.com/news/news-columns/analysis-indonesia-s-property-market-overviewforeign-ownership/item5728. 